\title{
STUDY OF INNOVATION IN LEARNING STYLES OF STUDENTS IN DIFFERENT SECONDARY SCHOOL BRANCHES
}

\author{
Masume Kalantari ${ }^{1}$ and Mohammad Tahan ${ }^{2}$ \\ ${ }^{I}$ Psychology and exceptional children training, Islamic Azad University, Tehran Branch, Iran \\ ${ }^{2}$ Department of Computer, University of Islamic Azad Ghaen Branch, Ghaen, Iran
}

\begin{abstract}
Learning, creativity, and innovation are considered as the axis of the activities of all educational and entrepreneur-based institutions. Learning style of students as one of the factors effective in learning and academic progress has always been taken into consideration. By identifying the learning style and rate of creativity of individuals, each style can be a more appropriate teaching method adopted by teachers and also a more correct method of learning by learners.

Accordingly, the main goal of the present article is to identify the differences of learning styles of individuals in different academic majors and the rate of the creativity of individuals in each learning style. The present methodology employed in this research is of descriptive-correlational research design. The statistical population consists of all the last-year students at the high school level in the city of Ghaen. The statistical sample consisted of 115 girls and 117 boys selected by classified sampling. Kolb's learning style inventory and Abedi creativity were used to collect the required data. These two tools are standardized, therefore their validity is verified. On the other hand, the reliability of the Kolb's inventory and that of Abedi's creativity were 0.74 and 79.5 , respectively. To analyze the data obtained by Chi-square tests, one-way analysis of variance, Pierson covariance, and stepwise regression were employed.

The results show that there is a meaningful difference between the creativity of the students with diverging and assimilator learning styles. Learning styles of students of different branches are also different. Creativity of the students of Mathematicsis more than that of the Humanities and there is also a meaningful negative relation between concrete experiential learning methods and creativity $(\mathrm{r}=0.702$ and $\mathrm{p}<0.01)$.
\end{abstract}

Keywords: Learning style, Creativity

\section{INTRODUCTION}

Due to their important and serious role in educating the future-making generation, educational institutions are considered as one of the important and fundamental institutions in society. One of the main preoccupations of educational system is to transfer knowledge to the future generation. Increasing production of knowledge and information; extensive cultural, social, and economic development and changes along with new problems and consequently new expectations for educational system have resulted in teaching the manner of learning and methods of creativity and innovation instead of the transfer of a collection of knowledge and information to individuals. In the present age, students should apply creative thought skills and correct learning methods to make appropriate decisions and solve the problems of society to cope with changes. Skinner believes that an effective educational system is based on appropriate learning and teaching methods for students (Mehyary, 2009). Creativity and innovation can also prepare the background for the growth and realization of talents as well as the self-prosperity of people. Of the most important places where talented 
people can grow are educational environments and teachers are of the group of people who can bring about creativity in students or inhibit creativity by the application of inappropriate methods (Kazemi, 2009). Most people can learn the manner of realizing creativity. The key to creativity is the development of some basic skills and abilities. All people are equally and potentially creative. Creative people are endowed with special skills. Every person can learn these skills, speed up the creativity process, and guide it. With regard to the role of the educational centers in fostering creativity and appropriate methods of teaching for better learning, it is therefore required to address this critical issue. In examining domestic and foreign literature, the researcher did not find any document regarding a study performed on the relation between learning style and rate of creativity in people. This research therefore intends to compare the rate of creativity of the subjects in each of the styles in addition to determining the learning style of each of the educational groups (experimental sciences, mathematics, and humanities) and inform the educational programmers of better teaching methods at the beginning of the academic year so as to help them to have access to more qualified strategies for the acquisition of science and knowledge.

Individual factors are considered as the integral components of creativity of people in most viewpoints and have been emphasized by researchers (Saadet, 2007). Of the most important individuallevel variables effective in creativity, one can refer to capability, personality features, cognition style, intelligence, and challengeable personality of people (Craft, 2001). In continuation, several examples of the researches performed in the area of learning styles and creativity are pointed out.

A research performed by Mehyaryet al. showed that A) There was a meaningful relation between the learning style and problem solving of university students. B) There was a meaningful difference among the learning styles of the students majoring in basic sciences, humanities, and technical-engineering disciplines, so that the students majoring in technicalengineering disciplines preferred sensory, general, active, and visual learning style, while those majoring in basic sciences preferred verbal, sequential, intuitive, and contemplative learning style, and on the other hand, students majoring in humanities mostly employed active learning style (Mehyary, 2009).

Rezaiet al. studied the learning style of the students of Arak School of medicinal Sciences. With regard to the dominant assimilator and convergent style of learning among the students, it was suggested that lectures and self-study along with reading materials, demonstration, and use of diagrams, teacher's handwriting, and one-to-one teaching be adopted. It was also suggested that the communication skills of the students of medicinal sciences be reinforced, since the assimilators and also convergent show less interest to subjects entailing cooperation with others (Rezai, 2008).

Sharifi et al. studied and compared the effect of three methods of fostering creativity on the enhancement of creativity in students. The results showed that regardless of the teaching method, creativity teaching helped the growth and fostering of creativity in students (Sharifi, 2008).

A research was also performed by Yazdi to study and compare the methods and styles of learning of the students at different colleges of Al-Zahra University. The results showed that the students at different colleges employed different methods and styles of learning. The students at the college of arts mostly employed concrete experiential method and divergent - accommodator styles; the students at the technical college used reflective observation, abstract conceptualization, and assimilator styles; those at the psychology college used active experimentation, abstract conceptualization, and convergent styles; and the students at the college of basic sciences also used abstract conceptualization and convergent styles (Yazdi, 2009).

Ross (2003) studied the learning styles and methods of problem solving. The goal of this research was to study the levels of motivation related to tourist industry and marketing experience. The results showed that those who avoided running tourist management enjoyed less creativity to trust preparation as a method for learning method, but they relied more on distance learning (Mehyary, 2009).

Sternberg performed a research on the effect of creativity on the performance of 110 students and concluded that the rate of the effect of creativity 
training stems from the cognition and personality traits of students (Sternberg, 2001).

The researches performed in relation to learning styles have shown that if individuals are trained with regard to their styles of learning and they know about their own style of learning, their learning will improve. (Mori, 1980; Spears, 1983; Settle, 1989; Clavass, 1994; and Lovelase, 2002 quoted by Ali Abadi, 2005).

\section{METHODOLOGY}

The present research is of correlational type in terms ofboth applicability and methodology. The variables of this research consists of different Kolb's learning styles (convergence, divergence, accommodative, and assimilator) as the predictor and incentive variables for the creativity of the students at high school level are the criterion variables. The present statistical population consists of all the last-year high school students (majoring in experimental sciences, humanities, and mathematics) in the academic year of 2013-2014. The classification method and Morgan Table were also employed for the selection and determination of the sample size, respectively. Then, the simple random method was used for the selection of the sample. Therefore, 115 girls and 117 boys were selected as the sample size. Kolb's learning style and Abedi's creative questionnaires were also used for the execution of the test.

The goal of Kolb's learning style questionnaire is to describe the manner of learner's learning and not to evaluate the learner's ability. There is no correct and incorrect answer in this questionnaire and all the choices are equally acceptable. The questionnaire consists of twelve questions classified into four sections of concrete experience (CE), reflective observation (RO), abstract conceptualization, and active experimentation (AE); each evaluating a part of the individual's ability. Since each of the learning styles is a combination of the above four learning methods, therefore justification of the type of learning style is based on the sum of these four scores representing four styles of learning specifying the individual's learning style. By the two-by-two subtraction of these styles, i.e. subtraction of abstract conceptualization from concrete experience and active experimentation from reflective observation, two scores are obtained. These two scores are then put on the coordinate axis. One is the vertical axis of AC-CE (concrete experience-abstract conceptualization) and the other is the horizontal axis of AE-RO (reflective observation-active experimentation) forming four quadrants of a square. These four quadrants of the square of the coordinate show the learning style of an individual (Gibbs, 2010). The validity and reliability of this tool has been verified in numerous researches including the present research. Therefore, the reliability of the present research based on Cronbach's alpha method shows a high coefficient.

Active experimentation, abstract conceptualization, reflective observation, and concrete experience were $0.83,0.74,0.71$, and 0.69 , respectively. On the whole, it was estimated to be 0.74 .

\section{Diagram 1. Manner of determining Kolb's learning style type}

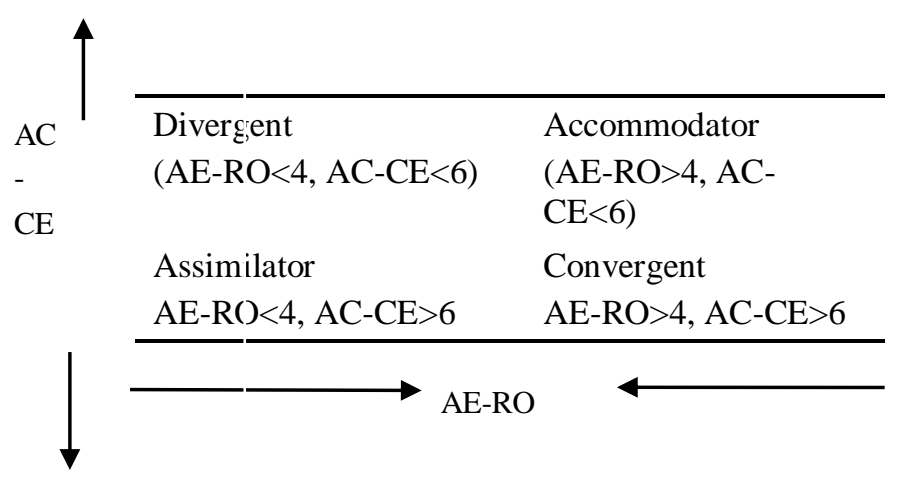

Abedi test was devised on the basis of the theory and definition of creativity by Torrance. The test is made up of four sub-tests of fluency, elaboration, originality, and flexibility. Each question consists of three choices. The choices reflect low, medium, and high originality with scores of 1, 2, and 3 for low, medium, and high originality, respectively. The sum of the scores acquired in the four sub-tests (fluency, elaboration, originality, and flexibility) show the overall score of creativity.

The validity of this questionnaire was checked by factor analysis and correlation with similar tests (Torrance); its reliability was checked by re-testing and Cronbach's alpha. The reliability of this test was also verified by the use of Cronbach's alpha in the present research. The flexibility, originality, elaboration, and fluency were $0.88,0.74,0.81$, and 
0.75 , respectively. On the other hand, in several researches including (Shahni et al, 2005) and (Sohrabi, 2002), the validity and reliability of this test were also verified by factor analysis, re-testing, and Cronbach's alpha.

\section{FINDINGS}

Research question: are there meaningful differences among learning styles of students majoring in different branches?

Table 2: contingency table of the variables of two learning styles and students of different branches

\begin{tabular}{|c|c|c|c|c|c|c|c|}
\hline \multirow[t]{2}{*}{ total } & \multirow{2}{*}{$\begin{array}{l}\text { Value } \\
\chi^{2}\end{array}$} & \multicolumn{6}{|c|}{ Learning styles } \\
\hline & & contingency & Assimilation & convergent & divergent & $\begin{array}{l}\text { Learning style } \\
\text { branch }\end{array}$ & \multirow{6}{*}{ 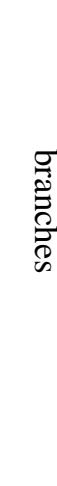 } \\
\hline 74 & 2.25 & 11 & 24 & 22 & 17 & mathematics & \\
\hline 85 & $* 4.60$ & 23 & 10 & 20 & 19 & humanities & \\
\hline 73 & 3.85 & 16 & 40 & 16 & 11 & $\begin{array}{l}\text { Experimental } \\
\text { Sciences }\end{array}$ & \\
\hline --- & --- & $* 15.68$ & 4.32 & 3.25 & $* 5.5$ & Value of $\chi^{2}$ & \\
\hline 219 & --- & 82 & 72 & 86 & 72 & Total & \\
\hline
\end{tabular}

$$
\chi^{2}=89.69 \mathrm{df}=6 \quad \mathrm{p}<0.01 *
$$

The above Table shows that the observed value of $\chi^{2}$ (89.69) is larger than that of $\chi^{2}$ the Table at $\mathrm{p}<0.01$ level, i.e. it can be said that there is a difference among the learning styles of the students and different majors at a confidence level of $99 \%$. Also, calculating the linear and columnar values of $\chi^{2}$, it was observed that the value of the linear $\chi^{2}$ was meaningful at a confidence level of $99 \%$, i.e. the learning style of humanities was meaningfully different and the most observed frequency was at the contingency style, but in calculating the columnar $\chi^{2}$, it was observed that the value of the $\chi^{2}$ of the convergent (3.25) and contingency (15.68) styles were significant at a confidence level of $99 \%$. With regard to the frequency of learning styles of the students in different majors, it can be said that most of the students in experimental branch used the convergent style and those in humanities used contingency style more than those in other majors.

Research question 2: is there any meaningful difference between the rates of the creativity of the students at high school level with regard to their learning styles?

Table 3. One - Way ANOVA

\begin{tabular}{llllll}
\hline $\begin{array}{l}\text { Sources of } \\
\text { changes }\end{array}$ & Sum of squares & Df & Df & F ratio & $\alpha$ \\
intergroup & 1181.613 & 2 & 393.871 & & \\
intragroup & & 217 & 111.982 & 3.517 & 0.016 \\
total & 23130.000 & 218 & & & \\
\hline
\end{tabular}

With regard to the results obtained from data analysis, it is observed that the calculated $F$ ratio for the purpose of comparing the creativity scores of the students on the basis of their learning styles is greater than that of the Table (at the error level of 0.05). It can therefore be concluded that there is a meaningful difference between the creativity rates of the students based on their learning styles. This ratio is only indicative of creativity difference in learning styles, but it does not identify where these differences are? 
Therefore, for the purpose of studying the meaningfulness of the mean difference of each group compared with that of another group, it seems necessary to perform a post-experimental or Tukey post-hoc test (HSD). The results obtained from the computation of the above test are presented in the following Table:

Table 4.Test-Tukey

\begin{tabular}{lllll}
\hline Statistical indices & Mean differences & Standard error & Significance level $(\alpha)$ \\
Learning styles & & & \\
Convergent & Contingency & 0.0707 & 2.912 & 0.195 \\
& divergent & 5.026 & 1.965 & 0.054 \\
Contingency & assimilator & -0.762 & 1.889 & 0.978 \\
& convergent & -0.707 & 2.912 & 0.495 \\
divergent & 4.318 & 2.924 & 0.453 \\
Divergent & assimilator & -1.470 & 2.873 & 0.956 \\
& convergent & -5.026 & 1.965 & 0.054 \\
& contingency & -4.318 & 2.924 & 0.453 \\
Assimilator & assimilator & $*-5.789$ & 1.906 & 0.014 \\
& convergent & 0.762 & 1.889 & 0.978 \\
& contingency & 1.470 & 2.873 & 0.956 \\
& divergent & $* 5.789$ & 1.906 & 0.014 \\
\hline
\end{tabular}

Mean difference at 5\% significance level

With regard to Tukey test, it is observed that there is a meaningful difference between the creativities of the students in the two styles of assimilator and divergent, in other words the creativity of the students employing the assimilator learning style is higher than those who use divergent learning style. Furthermore, with regard to the results obtained from the above Table, there is no meaningful difference between the creativity of the students in any other learning styles.
Research question 3: is there a meaningful relation between the learning styles of the students (concrete experience, reflective observation, abstract conceptualization, and active experimentation) with their creativity? To study the relation between learning styles and creativity of students, Pierson correlation test and stepwise regression were employed.

Table 4-A. Pierson correlation coefficient between learning styles and creativity

\begin{tabular}{lllll}
\hline $\begin{array}{l}\text { Learning } \\
\text { Components } \\
\text { creativity }\end{array}$ & $\begin{array}{l}\text { Concrete } \\
\text { experience }\end{array}$ & $\begin{array}{l}\text { Reflective } \\
\text { observation }\end{array}$ & $\begin{array}{l}\text { Abstract } \\
\text { conceptualization }\end{array}$ & $\begin{array}{l}\text { Active } \\
\text { experimentation }\end{array}$ \\
$\begin{array}{l}\text { Correlation coefficient } \\
\text { Significance level }\end{array}$ & 0.74 & 0.68 & 0.81 & 0.59 \\
& 0.000 & 0.000 & 0.000 & 0.000 \\
\hline
\end{tabular}


Table 4-B. results of multivariable correlation between learning styles and creativity

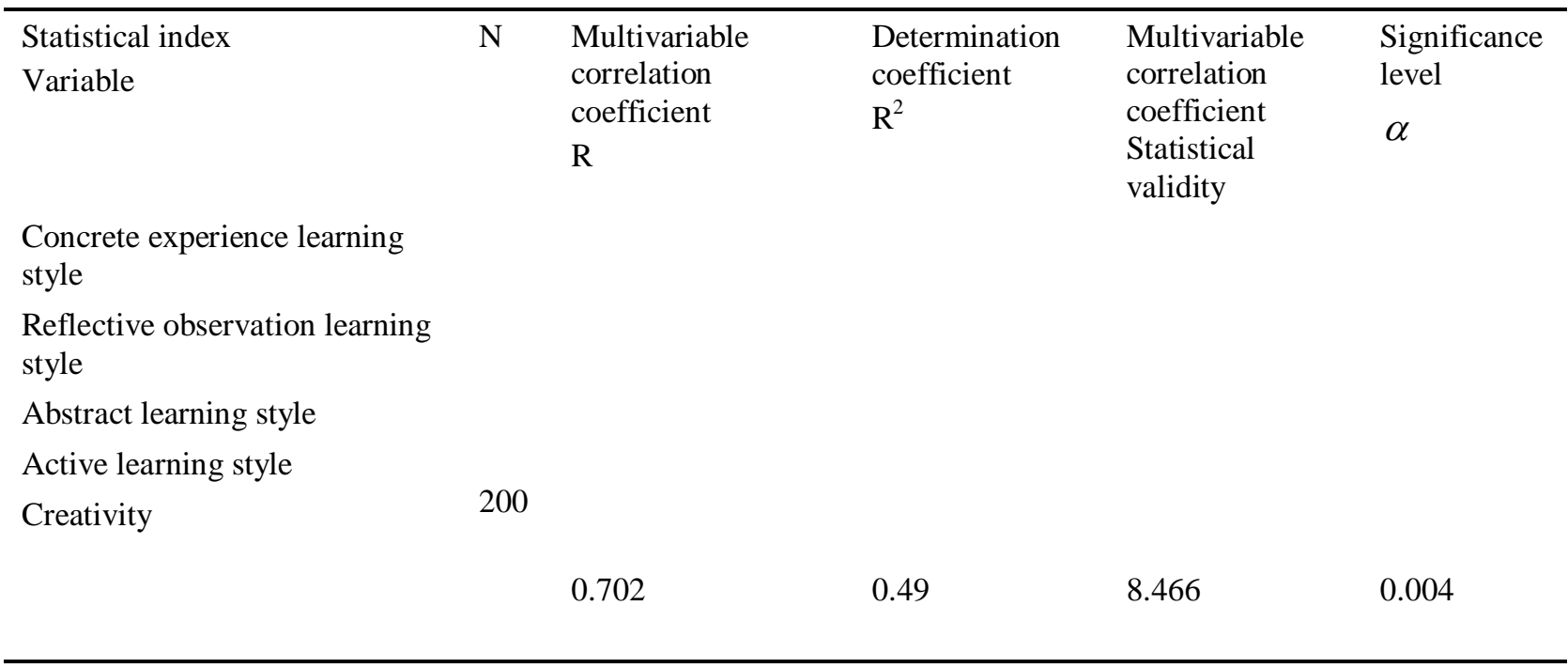

With regard to the results of the above Table, it is observed that the multivariable correlation coefficient between different learning styles and creativity score is 0.720 which is larger than the correlation coefficient of the Table at the confidence level of 0.01. Therefore, there is a meaningful relation between learning styles (concrete experience, reflective observation, abstract conceptualization, and active experimentation) and creativity of the students.

Furthermore, the computed value of $\left(R^{2}\right)$ is 0.49 indicating that $49 \%$ of the creativity scores is related to the learning styles (concrete experience, reflective observation, abstract conceptualization, and active experimentation) and the remaining $51 \%$ depends on factors outside the model. Since the computed correlation coefficient might be due to sampling error or random sampling, computation of $F$ ratio seems necessary. It should be specified whether the observed multivariable correlation coefficient after the computation of $F$ is meaningfully different from null hypothesis or not. By computing the value of $F$, it is observed that it is equal to 8.466, greater than that of the Table at the confidence level of 00.01. Therefore, the null hypothesis is rejected and the result is in conformity with the result obtained from the multivariable correlation coefficient. So, there is a meaningful relation between the learning styles (concrete experience, reflective observation, abstract conceptualization, and active experimentation) with creativity. From among the four styles (concrete experience, reflective observation, abstract conceptualization, and active experimentation), the

concrete experience learning style enjoyed the most correlation with creativity, with a correlation coefficient of 0.702 which is larger than that of the Table at the significant level of 0.01 . So, there is a meaningful relation between the learning style of concrete experience with creativity (by deleting reflective observation, abstract conceptualization, and active experimentation).

Table 5.Regression equation for the components of learning with creativity

\begin{tabular}{|c|c|c|c|c|c|}
\hline \multirow{2}{*}{$\begin{array}{l}\text { Statistical } \\
\text { index }\end{array}$} & \multicolumn{2}{|c|}{ Non-standard coefficients } & \multirow{2}{*}{$\begin{array}{l}\text { Standard } \\
\text { coefficient } \\
\beta\end{array}$} & \multirow{2}{*}{$\begin{array}{l}\text { Statistical validity of } \\
\text { correlation coefficient } \\
\mathrm{t}\end{array}$} & \multirow{2}{*}{$\begin{array}{l}\text { Significant } \\
\text { level } \\
\alpha\end{array}$} \\
\hline & B & $\begin{array}{l}\text { Standard } \\
\text { deviation }\end{array}$ & & & \\
\hline Constant & 131.97 & 3.58 & --- & 37.624 & 0.000 \\
\hline $\begin{array}{l}\text { Concrete } \\
\text { experience }\end{array}$ & -0.400 & 0.138 & 0.202 & -2.910 & 0.004 \\
\hline
\end{tabular}


As it is observed, the regression coefficient for the variable of concrete experience learning styles is equal to -0.4 according to the Table, while the result of the t-test shows the meaningfulness of this coefficient. The computed $t$ is larger than the $t$ of the Table at a significant level of 0.01 ; therefore, the null hypothesis is rejected. Therefore, there is a negative (reverse) meaningful relation between the concrete experience learning styles with creativity which is in conformity with the result obtained from correlation. In this analysis, the regression equation for the creativity of the students is: (concrete experience) 131.971-0.4 = creativity.

Research question 4: is there a meaningful difference among the creativity of the students of different majors (mathematics, humanities, and experimental sciences)?
To answer this research question, the one-way analysis of variance (ANOVA) was used. The results are presented in the following Table.

Table 6. Variance test

\begin{tabular}{llll}
\hline Significant level & df 2 & df 1 & value \\
0.269 & 217 & 2 & 1.344 \\
\hline
\end{tabular}

The results of the above Table show that statistically there is no meaningful difference among the variances of creativity of the students of different majors in the comparison test among the variances (pvalue $>0.05$ ). But, the results of Table 7 show that there is a meaningful difference among the creativity means in different majors.

Table 7.Regression equation of learning components with creativity

\begin{tabular}{llllll}
\hline Sources of changes & $\begin{array}{l}\text { Sum of the squares } \\
\text { Intergroup }\end{array}$ & $\begin{array}{l}\text { df } \\
\text { Intragroup }\end{array}$ & $\begin{array}{l}\text { Sum of squares } \\
\text { df }\end{array}$ & $\begin{array}{l}F \text { ratio } \\
\text { Significant level } \\
\alpha\end{array}$ \\
Total & 197007.638 & 2 & 19.570 & & \\
\hline
\end{tabular}

With regard to the data analysis, it is observed that the $F$ ratio computed for the purpose of comparing the creativity scores of the students in different majors (2.534) was greater than the Table $F$ (at 0.05 levels). Therefore, it can be concluded that there is a meaningful difference among the rates of the creativity of the students of different majors. The results obtained from the computation of the postexperimental or Tukey post-hoc test (HSD) are presented in the following Table:

Table 8. Tukey Test

\begin{tabular}{lllll}
\hline $\begin{array}{l}\text { Statistical index } \\
\text { Major }\end{array}$ & & Mean difference & Standard error (SE) & $\begin{array}{l}\text { Significant level } \\
(\alpha)\end{array}$ \\
mathematics & humanities & $* 0.2200$ & 0.05382 & 0.000 \\
& experimental & 0.1200 & 0.05444 & 0.124 \\
experimental & humanities & 0.0700 & 0.05002 & 0.500 \\
& mathematics & -0.1200 & 0.05444 & 0.124 \\
humanities & mathematics & $*-0.2200$ & 0.05832 & 0.000 \\
& experimental & -0.0700 & 0.5002 & 0.500 \\
\hline
\end{tabular}

With regard to the Tukey test it is observed that there is a meaningful difference between the creativity of the students in humanities and mathematics majors.
In other words, the mathematics students enjoy more creativity relative to those in humanities. But, there is no meaningful difference between the creativity of the students majoring in experimental and humanities 
as well as students majoring in experimental and mathematics.

\section{DISCUSSION AND CONCLUSION}

Question 1) the results show that there is a meaningful difference between the students learning styles and their majors. This difference stems from humanities. With regard to the abundance of styles in different branches, it can be said that most of the students majoring in experimental sciences use the convergence style and those in humanities use the contingency style more than other majors, while those majoring in mathematics use the assimilation style. These findings are similar to those of Yazdi (2001) and Masoumifard (2010).

Question 2) the results of the research witness the fact that there is a meaningful difference between the creativity mean of the students on basis of learning styles and this difference results from the creativity score of the students in two styles of assimilation and divergent; in other words, the creativity of the students who use the assimilation learning style is more than those using divergent learning style. The findings are consistent with those of Lorgani (1998), Miranssari (2000), Rezai(2008), and Anderson (1998). Since different styles of learning affect the creativity and academic achievement of students, it is therefore required that teachers be aware of the manner and types of learning so that they can help their students in optimal use of different learning styles (Seif2000). Schneider also believes that since individuals are different, we should therefore recognize their differences and coordinate ourselves with them. Also, according to Kolb's theory, those who use the assimilation style enjoy higher ability for acquiring information, memorizing, and saving it in their minds. These people enjoy the ability to combine information in a justified and logical manner and pay more attention to the logic of a theory.

Question 3) the results confirm that there is a meaningful relation between the scores of learning style (concrete experience, reflective observation, abstract conceptualization, and active experimentation) with the creativity of the students. The findings of this research are consistent with the findings of (Rahbar, 2005), Talebi (2002), Amirkhani (2003), and Barari (2008). According to Kolb and
Fry, the learner requires four types of abilities to function effectively: concrete experience, reflective observation, abstract conceptualization, and active experimentation. That is, the learner should be able to completely, willingly, and without bias involve himself with experiences; he should be able to observe these experiences from different viewpoints and reflect on them. He should be able to create concepts and merge his observations with logically right theories. He should be able to use these theories to make decisions and solve problems.

Question 4) results show that there is a meaningful difference among the rates of creativity of the students in different majors and this difference results from the creativity of the students majoring in humanities and mathematics. Therefore, the students majoring in mathematics enjoy more creativity relative to the students in humanities. The findings of this research are in conformity with those of Barari (2008), Valleyzadeh(2007), and Rezai(2008).

With regard to the results, it is proposed that:

A) Educational planning and suitable teaching methods of learning styles for the students majoring in different disciplines seem to be necessary for an increase in the rate of creativity of the students and reduction of creativity difference of students in different majors.

B) Through familiarity with learning styles, teachers and educational planners can conform planning and educational methods to the learning styles of the learners.

C) Teachers should accept the fact that each student might adopt a special style of learning for different subjects, so they have to adopt an appropriate style and method of learning for each student.

D) Informing the individual of his learning style can prepare his background knowledge to adopt optimal methods for learning.

\section{REFERENCES}

Abedi, J. (2002). A latent-Variable modeling approach to assessing reliability and validity of a creativity instrument. Creativity Research Journal, 14 (2), pp. 267276. 
Abedi, Joseph. (2010). How to take conflict management strategies among the librarians of public libraries: The role of creativity. Inform research and public libraries, Volume 16, Number 2, pp. 29-44.

Aliabadi, Khadija. (2005). Learning styles inventory of Down, Down and Price learning styles of fifth grade students and third grade students in Tehran in the year 2002-2003. PhD thesis, Allameh Tababai University, Faculty of Psychology and Educational Sciences.

Amirkhani, Jaleh. (2003). examining the relationship between thinking styles of teachers and students and its impact on student learning and achievement. M.Sc. Thesis, Islamic Azad University Tehran Central.

Andersson, A.L. \& Ryhammer, 'Psychoanalytic models of the mind, creative functioning and perceptgenetic reconstruction' in Psychoanalysis and Contemporary Thought, 21, 1998, pages 359-382

Barari, Mohsen. (2008). examining the relationship between the tetragonal Kolb learning styles and academic achievement of students at university of Mazanderan. M.Sc. thesis, University of Mazanderan, faculty of humanities and social sciences.

Craft, A, Jeffrey, B, Leibling, M, Creativity in education: current perspectives on policy and practice, Cassell, London, 2001 [in press]

Gibbs, Mike \& Helena Priest. (2010). Exploring the physical health needs of people with learning disabilities: Facilitation student engagement in learning, using Kolb's experiential learning cycle. Nurse Education in Practice, Volume 10, Issue 3. Pages 115118

Kazemi, Yahya, N. Jafari. (2008). Inhibitors of student's creativity: activities and teacher characteristics. Journal of Modern Educational Thought, Volume 4, Number 1 and 2.

Lorgani, Maryam. (1998), Comparison between the students learning style of three fields of Medicine, Technical - Engineering and Humanities of Allameh Tabatabai University. M.Sc. Thesis, Faculty of Psychology and Educational Sciences, Allameh Tabatabaei University.

Masoumi fard, Marjan. (2010). Study of the relationship between learning styles (visual, verbal, reading/writing, movement, multi-senses) of Payam Noor Center of Tehran University students with academic achievement. M.Sc. Thesis, Tehran Payam Noor University.

Mehyary, Azam \& Sabori \& Biglari Khani. (2009). Comparison of learning style first and fifth year students in medicine and its relationship with academic achievement. Journal of steps in the development of Medical Education. Volume 6, No. 2, pp. 118-110.

Mehyary, Azam. Mehdi, Khani. Biglari, Ibrahim. Khoshreftar, Amin. Bighlerkhony. (2009). styles of first year students in medicine University of Medical Sciences. Journal of Evolution and Development of Medical Education. Volume 1.

Rahbar, Afsaneh. (2005). investigates the relationship between girl students' learning styles of first year of the
Isfahan 13th district state high school and academic achievement in the academic year 2004-2005. MS thesis, University Khorsgan Islamic Azad University.

Rezai, Kourosh, Koohestani, F. Gangeh, Zoreh Anvary. (2008). Learning Style of freshman students of Arak University of Medical Sciences. Journal of Arak University, Year 12, No. 4, special issue 1.

Ross, Glenn. (2003). Ethical Beliefs, Work Problem Solving Strategies And Learning Styles as Mediators Of Tourism Marketing Entrepreneurialism. Journal of Wacation Marketing, London: Mar.Vol.9.Iss.2, Pp. 118119.

Saadet, Esfandiar and Sadeghi, M. (2005). Model to explain the design and creativity in preparing the groundwork for the country's research institutes. Journal of Daneshvar Behavior, 14, pp. 35-46.

Saif, Aliakbar. (2000). Psychological development, fifth edition, Tehran: Agah Publications

Shahni, Manijeh, S, F and Shokrkon, H. (2005). The effect of education brainstorming Creative student's chamran University of Ahvaz shahid intelligence control. Journal of Education and Psychology. The third period, the twelfth year, No. 1, p. 9 .

Sharifi, Hussein Pasha. (2008). the relationship between creativity and personality traits of high school students in Tehran. Journal of Educational innovations, No. 7, Third year, pp.11-32.

Sohrabi, Nazanin, Sohrabi. (2002). Evaluation of creativity and psychological pressure on drug groups, drug traffickers and normal samples and review the relationship between creativity and psychological pressure, addiction and challenges Congress, November.pp 56-78.

Sternberg. (2001). it doesn't to add: Effect of instruction to be creative. Creative Research Journal, V. 13, N 2, Pages 197-210.

Talebi, Narges. (2002). examining the relationship between personality types and learning styles of female students in Tehran. MS thesis, Tehran University, faculty of humanities and social sciences.

Valleyzadeh, Leila, Eskandar Fathi Azar, Vahid, Zamanzadeh. (2007). Features associated with the learning progress of students of nursing and midwifery. Iranian Journal of Medical Education, Volume 7, Issue 2, pp. 443-450.

Yazdi, Monavver. (2001). Review and comparison of different learning styles of students of Alzahra University. Educational Research journal of Andishe Nevin, vol. 5, no.2, summer, pp.123-145 